\title{
Cleavage Site Specificities of Silkworm Alkaline Proteases
}

\author{
Takuji SASAKI,* Masayasu Morishita and Munehiro ISE \\ Department of Food Science and Technology, School of Agriculture, \\ Nagoya University, Chikusa, Nagoya 464, Japan
}

Received March 25, 1985

\begin{abstract}
The cleavage site specificities of two alkaline proteases isolated from digestive juice of the silkworm larva, Bombyx mori, were analyzed using insulin A and B chains, $\alpha$-lactalbumin, and egg white lysozyme. One, named P-IIc, could cut Arg-X and Lys-X peptide bonds and another, named P-IIIa, required rather hydrophobic amino acids not only at P1 but also at P4 sites. The effects of some protease inhibitors on P-IIIa could be explained by this requirement.
\end{abstract}

The silkworm larva, Bombyx mori, contains alkaline proteases in its midgut digestive juice. Upon purification, two kinds of alkaline serine proteases were found, each of which was further separated into three isozymes. ${ }^{1)}$ One named P-II has its $\mathrm{pH}$ optimum at about 10 , and can hydrolyze benzoyl-L-arginine $p$-nitroanilide (Bz-Arg-pNA). Another, named PIII, has its $\mathrm{pH}$ optimum for hydrolyzing casein at about 11 but cannot hydrolyze any of the synthetic substrates tried, such as Bz-ArgpNA, benzoyl-L-tyrosine $p$-nitroanilide (BzTyr-pNA), and glutaryl-L-phenylalanine $p$ nitroanilide (Glt-Phe-pNA). The effects of inhibitors on P-III are complicated, that is, chymostatin, a chymotrypsin-like protease inhibitor of microbial origin, ${ }^{2)}$ and soybean Bowman-Birk inhibitor can inhibit P-III, but tosyl-L-phenylalanine chloromethylketone (TPCK) and low molecular weight silkworm chymotrypsin inhibitor $(\mathrm{SCI})^{3)}$ cannot. To settle these problems, it is necessary to find the cleavage site specificity using peptides or proteins as substrates. In this report, we describe the estimated cleavage site specificities of P-II and especially those of P-III.

\section{MATERIALS AND METHODS}

The silkworm alkaline proteases, P-IIc and P-IIIa, were prepared from midgut digestive juice of silkworm larva by the method of Sasaki and Suzuki. ${ }^{1)}$ Oxidized insulin A and B chains were purchased from Sigma, U.S.A. and Behringer Mannheim, West Germany, respectively. Egg white lysozyme and $\alpha$-lactalbumin were from Sigma, and they were S-carboxymethylated by the method of Hirs. ${ }^{4)}$ Proteolytic digestion was done in ammonium carbonate buffer, $\mathrm{pH} 9.6$, at $35^{\circ} \mathrm{C}$ for $120 \mathrm{~min}$ with substrate $:$ enzyme $=200: 1(\mathrm{w} / \mathrm{w})$. The reaction was stopped by acidification and the peptide mixture was lyophilized. In case of lysozyme and $\alpha$-lactalbumin, peptides were separated with DEAE-Sephadex A-25 or SP-Sephadex C25 and further purified with Sephadex G-25 or Bio-Gel P10 .

Amino acid analyses of peptides were done with a JEOL JLC-8AH amino acid analyzer after hydrolyses in $6 \mathrm{~N} \mathrm{HCl}$ at $110^{\circ} \mathrm{C}$ for $22 \mathrm{hr}$. N-terminal sequence analyses of peptides were done manually by the method of Edman ${ }^{5)}$ from the 1st to the 5th cycle and the phenylthio-hydantoin amino acid derivatives obtained were identified by high performance liquid chromatography using JASCO Finepak SIL $\mathrm{C}_{18}$ by the method of Bhown et al. ${ }^{6)} \mathrm{C}$ Terminal amino acids were identified by the hydrazinolysis method $^{7)}$ or by using carboxypeptidase $Y^{8}{ }^{8}$

Human serum $\alpha$-1-proteinase inhibitor and $\alpha-1$ antichymotrypsin were prepared by Travis and Johnson's method $^{9)}$ and that of Katsunuma et al., ${ }^{10)}$ respectively. Streptomyces subtilisin inhibitor (SSI) ${ }^{11)}$ was a generous gift from Dr.B.Tonomura of Kyoto University. Residual activity of P-IIIa after a 5-min reaction with each protease was assayed by using casein as the substrate at $\mathrm{pH} 9.5$.

Succinyl-L-leucyl-L-leucyl-L-valyl-L-tyrosine 4-methylcoumaryl-7-amide (Suc-Leu-Leu-Val-Tyr-MCA) and 7amino-4-methylcoumarin (AMC) were purchased from the Protein Research Foundation, Osaka, and the activity assay of P-IIIa using Suc-Leu-Leu-Val-Tyr-MCA at pH

* To whom all correspondence should be addressed. 
10.0 was that of Kato et al. ${ }^{12)}$ using a JASCO fluorescence spectrophotometer model FP-550A. Apparent kinetic constants were estimated from Lineweaver-Burk plots.

\section{RESULTS AND DISCUSSION}

In Fig.1, the sites of insulin A and B chains cleaved by P-IIc and P-IIIa, which are the predominant isozymes of the P-II and P-III groups, respectively, are shown. P-IIc can cleave $\operatorname{Arg}_{22}-\mathrm{Gly}_{23}$ bonds in the B chain and cannot hydrolyze any peptide bonds in the A chain. The inhibition experiment showed that tosyl-L-lysine chloromethylketone (TLCK) was effective on P-IIc, ${ }^{1)}$ so $\alpha$-lactalbumin, which contained only one arginine and twelve lysine residues, and lysozyme, which contains eleven arginine and six lysine residues, were digested by P-IIc. The hydrazinolyses of the peptide mixtures obtained gave two free amino acids, lysine, and ornithine derived from arginine, and their ratio were $1: 5.8$ (Arg: Lys) in $\alpha$-lactalbumin and 1:0.1 (Arg: Lys) in lysozyme. These results indicate that P-IIc can hydrolyze both Arg-X and Lys-X bonds, but prefers the former. Judging from the failure of hydrolysis of the $\mathrm{Lys}_{29}-\mathrm{Ala}_{30}$ bond in the insulin B chain, P-IIc may have no exopeptidase activity.

On the other hand, P-IIIa can cut the $\mathrm{Leu}_{15^{-}}$ $\mathrm{Tyr}_{16}$ bond in the insulin $\mathrm{B}$ chain and the $\mathrm{Leu}_{13}-\mathrm{Tyr}_{14}$ bond in the A chain. To confirm whether P-IIIa can cleave only this peptide bond or not, $\alpha$-lactalbumin and lysozyme were digested by P-IIIa. In Table I, the peptide bonds mainly attacked by P-IIIa are listed. The yields of each peptide are also included in Table I. The peptides obtained are well aligned from the amino- to carboxy-termini without lack of any segments when their amino acid composition and partial amino acid sequences were assigned to the established amino acid sequence of each protein. It becomes clear that amino acid residues at $P 1^{13)}$ are not restricted to Leu but are generally hydrophobic or have hydrophobic parts in their side chains, and that, in addition, those at $\mathrm{P} 4$ also possess such characteristics. This is also applicable to the insulin A and $B$ chains (Table I). In the natural substrates used here, there also exist other peptide bonds that should be hydrolyzed by P-IIIa, but they remain uncleaved. We cannot now resolve this discrepancy, but factors such as conformation of peptide chains or steric hindrances may influence the efficiency of hydrolysis.

As already reported, ${ }^{1)}$ P-IIIa could not hydrolyze Bz-Tyr-pNA or Glt-Phe-pNA which have hydrophobic amino acids only at P1. On the basis of the results mentioned above, we tried to use a new synthetic substrate, Suc-LeuLeu-Val-Tyr-MCA, which had hydrophobic amino acid at both $\mathrm{P} 1$ and $\mathrm{P} 4$ positions. As expected, P-IIIa can hydrolyze this substrate with apparent $K m=3.5 \cdot 10^{-6} \mathrm{M}$ and $V_{\max }=$ $47.1(\mu \mathrm{mol} \mathrm{AMC} / \mathrm{min} / \mathrm{mg}$ P-IIIa $)$ at $\mathrm{pH} 10.0$ at $35^{\circ} \mathrm{C}$.

The importance of the amino acids at P1 and P4 is also deduced from the interaction of P-IIIa with several protease inhibitors. Also as reported, ${ }^{1)}$ chymostatin (P1-phenylalaninal, P4-Ile $)^{2)}$ and soybean Bowman-Birk inhibitor (Pl-Leu, P4-Ile) ${ }^{14)}$ are inhibitory, or bind to the active site of P-IIIa, but silkworm chymotrypsin inhibitor (P1-Phe, P4-Gly) ${ }^{3)}$ is not. We investigated other protease inhibitors and as shown in Fig. 2, the most effective inhibitor is human $\alpha$-1-antichymotrypsin (P1-Leu, P4Ile) ${ }^{15)}$; human $\alpha$-1-proteinase inhibitor (P1Met, P4-Ala $)^{16)}$ is weakly inhibitory and SSI (P1-Met, P4-Met $)^{17)}$ is not. These results sup-

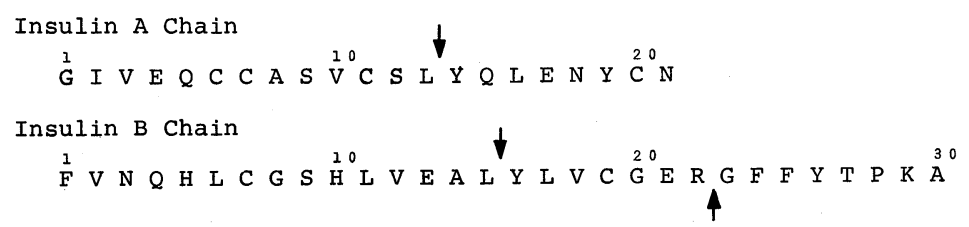

FIG. 1. The Cleaved Sites of Oxidized Insulin A Chain and B Chain by Silkworm Alkaline Proteases, P-IIc $(\uparrow)$ and P-IIIa $(\downarrow)$. 
Table I. Summary of Preferred Amino Acid SeQuence as Substrate for Silkworm Alkaline Protease, P-IIIa

\begin{tabular}{|c|c|c|c|c|c|c|c|c|}
\hline P5 & P4 & P3 & $\mathrm{P} 2$ & P1 & $\mathrm{P} 1^{\prime}$ & $\mathrm{P} 2^{\prime}$ & $\begin{array}{c}\text { Yield of } \\
\text { peptide } \\
(\%)^{a}\end{array}$ & Source $^{b}$ \\
\hline $\mathrm{S}$ & V & $\mathrm{C}$ & $\mathrm{S}$ & $\mathrm{L}_{15}$ & $Y_{16}$ & Q & N.D. ${ }^{c}$ & 1 \\
\hline $\mathrm{L}$ & V & $\mathrm{E}$ & A & $\mathrm{L}_{13}$ & $Y_{14}$ & $\mathrm{~L}$ & N.D. ${ }^{c}$ & 2 \\
\hline D & $\mathrm{L}$ & $\mathrm{K}$ & G & $Y_{18}$ & $\mathrm{G}_{19}$ & $\mathrm{G}$ & 22 & 3 \\
\hline $\mathrm{E}$ & W & V & $\mathrm{C}$ & $\mathrm{T}_{29}$ & $\mathrm{~T}_{30}$ & $\mathrm{~K}$ & 11 & 3 \\
\hline $\mathrm{L}$ & $\mathrm{F}$ & $Q$ & I & $\mathrm{N}_{56}$ & $\mathrm{~N}_{57}$ & $\mathrm{~K}$ & 18 & 3 \\
\hline $\mathrm{N}$ & I & $\mathbf{M}$ & $\mathrm{C}$ & $V_{92}$ & $\mathrm{~K}_{93}$ & $\mathrm{~K}$ & 22 & 3 \\
\hline G & I & $\mathbf{N}$ & $\mathrm{Y}$ & $\mathrm{W}_{104}$ & $\mathrm{~L}_{105}$ & A & 15 & 3 \\
\hline A & $\mathrm{H}$ & $\mathrm{K}$ & A & $\mathrm{L}_{110}$ & $\mathrm{C}_{111}$ & $\mathrm{~S}$ & 19 & 3 \\
\hline $\mathrm{L}$ & A & A & A & $\mathrm{M}_{12}$ & $\mathrm{~K}_{13}$ & $\mathrm{R}$ & 8 & 4 \\
\hline A & $\mathbf{M}$ & $\mathrm{K}$ & $\mathrm{R}$ & $\mathrm{H}_{15}$ & $\mathrm{G}_{16}$ & $\mathrm{~L}$ & 17 & 4 \\
\hline G & L & D & $\mathrm{N}$ & $Y_{20}$ & $\mathrm{R}_{21}$ & G & 32 & 4 \\
\hline $\mathrm{N}$ & $Y$ & $\mathrm{R}$ & $\mathrm{G}$ & $Y_{23}$ & $\mathrm{~S}_{24}$ & $\mathrm{~L}$ & 14 & 4 \\
\hline $\mathrm{N}$ & W & V & $\mathrm{C}$ & $A_{31}$ & $\mathrm{~A}_{32}$ & $\mathrm{~K}$ & 21 & 4 \\
\hline $\mathrm{C}$ & A & A & $\mathrm{K}$ & $\mathrm{F}_{34}$ & $\mathrm{E}_{35}$ & $\mathrm{Y}$ & 22 & 4 \\
\hline Q & A & $\mathrm{T}$ & $\mathrm{N}$ & $\mathrm{R}_{45}$ & $\mathrm{~N}_{46}$ & $\mathrm{~T}$ & 13 & 4 \\
\hline I & L & $\mathrm{Q}$ & I & $\mathrm{N}_{59}$ & $S_{60}$ & $\mathrm{R}$ & 8 & 4 \\
\hline D & I & $\mathrm{T}$ & A & $S_{91}$ & $V_{92}$ & $\mathrm{~N}$ & 16 & 4 \\
\hline G & $\mathbf{M}$ & $\mathrm{N}$ & A & $\mathrm{W}_{108}$ & $V_{109}$ & A & 37 & 4 \\
\hline D & $\mathrm{V}$ & $\mathrm{Q}$ & A & $\mathrm{W}_{123}$ & $\mathrm{I}_{124}$ & $\mathrm{R}$ & 14 & 4 \\
\hline
\end{tabular}

a The value is for the peptide having newly appeared amino terminal residue, $\mathrm{P}^{\prime}$.

${ }^{b}$ 1, oxidized insulin A chain; 2, oxidized insulin B chain; 3 , S-carboxymethylated $\alpha$-lactalbumin; 4 , Scarboxymethylated lysozyme. Amino acids are indicated in one-letter symbols and the suffixes mean the numbering of residues from $\mathrm{N}$-terminus of each protein.

c Not determined.

port the proposed idea of P-IIIa specificity to some extent.

The comparison of these characteristics of P-IIIa with those of other serine proteases seems to be important in interpreting the conception of "secondary interaction". ${ }^{18)}$ Elongation of a synthetic peptide substrate in the amino terminus direction from the scissile bond generally produces an increase in $k_{\text {cat }} / K m \cdot{ }^{19,20)}$ This implies that the active sites of serine proteases are grooves constructed by some amino acids and the effect of secondary interaction is just like an anchor. The importance of the amino acid at the P4 subsite in peptide bond hydrolysis was also indicated as for chymotrypsin, ${ }^{21)}$ but no protease besides $\mathrm{P}$ IIIa essentially requires this anchor at $\mathrm{P} 4$. The

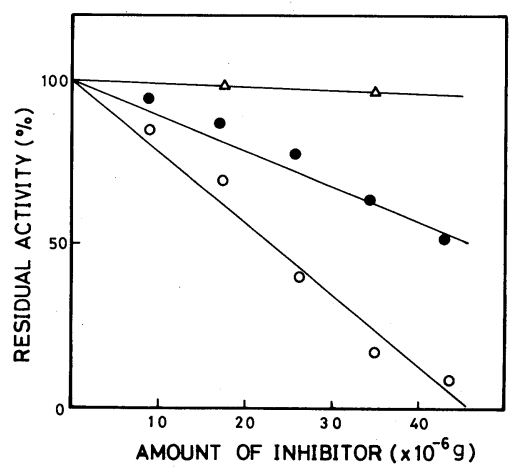

FIG. 2. Plot of Residual Activity of P-IIIa $v s$. Amount of Inhibitor Added.

Residual activity of P-IIIa $(4.3 \mu \mathrm{g}) 5 \mathrm{~min}$ after incubation with each protease inhibitor was assayed by adding $1 \%$ casein solution to this reaction mixture at $\mathrm{pH} 9.5$ at $35^{\circ} \mathrm{C}$. After $20 \mathrm{~min}$, trichloroacetic acid was added to a final concentration of $3 \%$ and the absorbancy of the supernatant at $280 \mathrm{~nm}$ was measured.

$\bigcirc-\bigcirc, \alpha$-1-antichymotrypsin; - $-\alpha$-1-proteinase inhibitor; $\triangle-\triangle$, SSI.

silkworm alkaline protease P-IIIa should have a hydrophobic subsite at S4 and in substrate hydrolysis, the fixation of the P4 site of substrate to $\mathrm{S} 4$ should be primarily required.

Substrate specificities of alkaline proteases in silkworm larval digestive juice are also interesting with regard to the appearance of toxicity from the protoxin produced by Bacillus thuringiensis. Details of the breakdown from protoxin to toxin are still not clear, but it is believed that some proteolytic activity participates in this conversion. The result just mentioned above may contribute to solve such problems.

\section{REFERENCES}

1) T. Sasaki and Y. Suzuki, Biochim. Biophys. Acta, 703, 1 (1982).

2) H. Umezawa, T. Aoyagi, H. Morishima, S. Kunimoto, M. Matsuzaki, M. Hamada and T. Takeuchi, J. Antibiot., 23, 423 (1970).

3) T. Sasaki, FEBS Lett., 168, 227 (1984).

4) C. H. W. Hirs, "Methods in Enzymology," Vol. 11, ed. by C. H. W. Hirs, Academic Press Inc., New York, 1967, p. 199.

5) P. Edman and A. Henschen, "Protein Sequence Determination," ed. by S. B. Needleman, SpringerVerlag, Berlin, 1975, p. 232. 
6) A. S. Bhown, J. E. Mole, A. Weidsinger and J. C. Bennett, J. Chromatogr., 148, 532 (1978).

7) K. Narita, H. Matsuo and T. Nakajima, "Protein Sequence Determination," ed. by S. B. Needleman, Springer-Verlag, Berlin, 1975, p. 70.

8) R. Hayashi, "Method in Enzymology," Vol. 45, ed. by L. Lorand, Academic Press Inc., New York, 1976, p. 568.

9) J. Travis and D. Johnson, "Methods in Enzymology," Vol. 80, ed. by L. Lorand, Academic Press Inc., New York, 1981, p. 754.

10) T. Katsunuma, M. Tsuda, T. Kusumi, T. Ohkubo, T. Mitomi, H. Nakasaki, T. Tajima, S. Yokoyama, H. Kamiguchi, K. Kobayashi and H. Shinoda, Biochem. Biophys. Res. Commun., 93, 552 (1980).

11) S. Murao and S. Sato, Agric. Biol. Chem., 36, 160 (1972).

12) H. Kato, N. Adachi, Y. Ohno, S. Iwanaga, K. Takada and S. Sakakibara, J. Biochem., 88, 183
(1980).

13) I. Schechter and A. Berger, Biochem. Biophys. Res. Commun., 27, 157 (1967).

14) S. Odani and T. Ikenaka, J. Biochem., 71, 839 (1972).

15) T. Chandra, R. Stackhouse, V. J. Kidd, K. J. H. Robson and S. L. C. Woo, Biochemistry, 22, 5055 (1983).

16) R. W. Carrell, J.-O. Jeppsson, C.-B. Laurell, S. O. Brennan, M. C. Owen, L. Vaughan and D. R. Boswell, Nature, 298, 329 (1982).

17) T. Ikenaka, S. Odani, M. Sakai, Y. Nabeshima, S. Sato and S. Murao, J. Biochem., 76, 1191 (1974).

18) J. S. Fruton, "Advances in Enzymology," Vol. 33, ed. by F. F. Fruton, Interscience Publishers, New York, 1970, p. 401.

19) K. Morihara and T. Oka, FEBS Lett., 33, 54 (1973).

20) C.-A. Bauer R. C. Thompson and E. R. Blout, Biochemistry, 15, 1291 (1976).

21) H. T. Wright, Eur. J. Biochem., 73, 567 (1977). 